\title{
Canadian Brain and Nerve Health Coalition (CBANHC)
}

The main advocacy program of the CNSF is CBANHC, a coalition of representatives from the CNSF, voluntary health organizations, the Canadian Association of Neuroscience Nurses, the Canadian Association for Neuroscience and Neuro-Science Canada. Following the release in June 2007 of a CBANHC-sponsored study ${ }^{1}$ that documented the economic and disability burden of several of the most common disorders of the nervous system, the CNSF Board of Directors created a Task Force to review the future role of CBANHC. In December, 2008, the Board approved the recommendations of the Task Force that:

- CNSF continue to support CBANHC as its advocacy vehicle;

- The revised mission statement and goals, be adopted;

- $\quad$ CBANHC aim to achieve its goals through strategic alliances with other health-related coalitions and organizations;

- CBANHC review its internal governance and infrastructure support.

One of the great strengths of CBANHC has been its relationship to most of the key neuroscience-related voluntary health organizations. During the past year, a coalition of neurological agencies has come together under the name "Neurological Health Charities Canada" (NHCC). CBANHC has been kept informed about the activities of this important new group and is working with them to present a unified approach to the public and governments.

Charles Tator, who was Chair of CBANHC for more than 5 years, retired from the position at the end June, 2008. The CNSF is indebted to Charles for his wise, conscientious and dedicated leadership that did so much to make CBANHC the recognized advocacy program of the CNSF. Charles was also the driving force behind the effort that lead to the publication in 2007 of The Burden of Neurological Diseases, Disorders and Injuries in Canada as a joint report of the CNSF/CBANHC and the Canadian Institute for Health Information. This report continues to receive attention and has served as a resource for government and non-governmental organizations. Thankfully, CBANHC will continue to benefit from Charles' insights as a member of the CBANHC steering committee.

It is our pleasure to report that Richard Riopelle has agreed to serve as the next CBANHC Chair. Rick has considerable experience in advocacy and working with VHOs, including the NHCC. Rick's first task as Chair has been to put the revised CBANHC objectives into operation by working closely with the CNSF Executive Committee and Board to modify the CBANHC governance structure. He has also been actively promoting alliances with other groups concerning advocacy on behalf of patients with neurological disorders and injuries and their care-givers.

\section{BIOGRAPHICAL SKETCH}

R.J. Riopelle, MD, FRCPC, FCAHS is Professor and Chair, Department of Neurology and Neurosurgery, McGill University (2000-present). He has been stably funded by the peer funding system for research operations, and in 2004 licensed a large body of intellectual property to Painceptor Pharma inc. within which he is a founding shareholder.

In his current position Riopelle oversees the academic and/or clinical activities of 150 colleagues on 6 hospital sites and 3 research institutes/centres of the McGill academic health sciences network, the Graduate Training Program in Neurosciences (200 registrants), and the RCPSC training programs in Neurology and in Neurosurgery. Building on its foundations, and during his tenure as Chair, Riopelle has overseen and coordinated strategic recruitment of clinicians, scientists, and clinician-scientists as part of a program of growth, renewal, and retention that has consolidated the Department's position as the strongest academic department in McGill, well positioned to take advantage of the emerging science of integrated systems biology (ISB) applied to health issues, and to lead a robust knowledge mobilization thrust taking advantage of his broad engagement in initiatives to position the academic health neurosciences as a leader in health systems reforms designed to address the area of complex chronic neurological disorders prevention and management.

Riopelle has held leadership positions in professional bodies within the discipline of neuroscience; Canadian Neurological Society (president), Canadian Congress of Neurological Sciences (president), and Canadian Association of Neuroscience (councilor). He has had an enduring relationship with voluntary health organizations serving clients with mental and neurological disorders. It is anticipated that a synergy of activities in the areas of network building, surveys of burden of neurological disorders and attendant disability, and involvement in implementation research of innovations in practice will facilitate increased return on human, social, economic, and health capital for those with complex chronic disorders from a lifecourse perspective.

Riopelle has accumulated a significant body of experience in stakeholder needs-driven, client-focused regional health systems innovations using integration strategies emerging from academia in partnership with the Heart and Stroke Foundation of Ontario (HSFO) that informed decisions to create the Ontario Stroke Strategy. He is currently involved in a similar initiative in Quebec. The learnings emerging from these activities will inform a broader agenda on behalf of the neurological health charities of Canada and the clients, families, and professionals that they support.

\section{REFERENCE}

1. "Burden of Neurological Diseases, Disorders and Injuries in Canada" published by the Canadian Institute for Health Information (CIHI) 